\title{
Vitamin D Levels are found to be higher in Gestational Diabetics in Vitamin D Depleted Population
}

\author{
Savaș Ozdemir ${ }^{2}$, Alev Atis Aydin ${ }^{1 *}$, Deniz Acar ${ }^{1}$, Zuhat Acar ${ }^{1}$ and Burhanettin Sahin ${ }^{2}$ \\ ${ }^{1}$ Department of Feto-Maternal Medicine, University of Health Sciences, Istanbul Kanuni Sultan Suleyman Training and Research Hospital, Turkey \\ ${ }^{2}$ Department of Obstetrics \& Gynecology, Turkey
}

*Corresponding author: Alev Atis Aydin, obstetrician, University of Health Sciences, Istanbul Kanuni Sultan Suleyman Training \& Research Hospital, Kucukcekmece, Halkali, Istanbul, Turkey.

Received Date: June 18, 2020

Published Date: June 25, 2020

\begin{abstract}
Objective: Vitamin D levels are studied in Gestational Diabetes in many researches. Our aim is to investigate the relationship of vitamin D deficiency with gestational diabetes mellitus (GDM) in pregnancy.

Methods: In this study, 210 Pregnant women were included, of them 108 had GDM, 102 were controls. 25-hydroxyvitamin D (25(OH)D) levels of GDM group were compared with healthy pregnant controls. The maternal and fetal outcomes were recorded.

Results: GDM group had significantly higher mean 25(OH)D $(11.8 \pm 8.0 \mathrm{ng} / \mathrm{ml})$ compared to controls $(7.7 \pm 6.1 \mathrm{ng} / \mathrm{ml}$, p<0.01). There was no correlation of vitamin D levels with; maternal age, Apgar levels, birth week and fetal weight. Furthermore, there was no correlation of 25(OH)D levels with mode of delivery, intensive care need of new-born and macrosomia.

Conclusions: Although there are numerous reports about positive correlation between vitamin D deficiency and GDM in pregnancy, we found the opposite. In severe vitamin D deficiency, the mechanisms may differ and should be identified further.
\end{abstract}

Keywords: Gestational Diabetes; 250HD; Fetal; Maternal outcomes

\section{Introduction}

Deficiency of 25-hydroxyvitamin D [25(OH)D] levels are found to be correlated with many adverse pregnancy outcomes like preeclampsia, stillbirth, intrauterine growth retardation, gestational diabetes (GDM), preterm birth [1,2]. The major source of vitamin D in humans is ultraviolet B induced dermal synthesis of cholecalciferol, whereas food sources are believed to play a lesser role [3]. Factors like skin pigmentation, age, attire, environment and sun exposure affect this cycle. GDM is characterized by increased resistance to and impaired secretion of insulin, may affect up to $18 \%$ of pregnant women and results in higher risk of adverse pregnancy outcomes [4].
There isn't still full agreement on the association between GDM and vitamin D deficiency up till now $[1,2,5]$. Some studies report positive, some report negative or none association. Our aim is to investigate the correlation vitamin D deficiency with GDM in our vitamin D depleted population.

\section{Methods}

In this prospective cohort study, fasting serum levels of 25(OH) D were measured in pregnant women grouped according to Oral Glucose Tolerance Test (OGTT) at 24 weeks. 108 GDM patients and 102 normal healthy pregnant women were compared according to their fasting serum levels of 25(OH)D in second trimester after GDM 
screening (24-28 weeks of gestation). Vitamin D was measured by chemiluminescence assay and deficiency was defined as $<20 \mathrm{ng} /$ $\mathrm{mL}$. Participants were followed until puerperium. GDM screening is performed to the pregnant attending to our hospital.

For GDM, screening is done by one step 75 g OGTT. Diagnosis of GDM is confirmed if one of the glucose levels exceeds the IADPSG criteria (International Association of Diabetes Pregnancy Study Group): fasting $\geq 92 \mathrm{mg} / \mathrm{dl}$, 1 -hour $\geq 180 \mathrm{mg} / \mathrm{dl}$, 2-hour $\geq$ $153 \mathrm{mg} / \mathrm{dl}$ [4]. After reviewing the results of the HAPO Study, many international diabetes study groups, including the IADPSG and American Diabetes Association, have adopted the 75-g OGTT at 24-28 weeks as a screening and diagnostic test.
Body Mass Indexes (BMI) were calculated by weight/height2 and compared. After delivery, Maternal and infant medical outcomes were recorded. Gestational diabetes group (study group) compared with healthy pregnant regarding 25(OH)D levels at the same season (spring). Maternal and fetal outcomes were recorded in our hospital. The study was approved by Hospital's Ethics Committee.

Statistical analyses were performed using SPSS, version 16.0 (SPSS Inc, Chicago, Ill, USA). Student $\mathrm{t}$ test is used for parametric variables; $\chi 2$ square test is used for nonparametric variables. Pearson correlation analysis is used for normally distributed data. Relation of continuous variables with dichotom outcomes were analysed by Logistic regression analysis. A p value $<0.05$ was considered statistically significant.

Results

Table 1: Baseline characteristics.

\begin{tabular}{|c|c|c|c|}
\hline \multirow{3}{*}{ Variables } & Group 1 (study group) & Group 2(control) & \multirow[t]{3}{*}{$\mathbf{p}$} \\
\hline & N (108) & $\mathrm{N}(102)$ & \\
\hline & $(51 \%$ & $(49 \%$ & \\
\hline Age & $30,4 \pm 4,6$ & $27,6 \pm 6,3$ & $<0,01$ \\
\hline Gravidity & $2,8 \pm 1,4$ & $2,5 \pm 1,5$ & $>0,05$ \\
\hline Parity & $1,3 \pm 1,1$ & $1,2 \pm 1,2$ & $>0,05$ \\
\hline Birth Week & $38,2 \pm 1,5$ & $38,4 \pm 1,3$ & $>0,05$ \\
\hline Birth Weight (gr) & $3400 \pm 500$ & $3200 \pm 500$ & $<0,01$ \\
\hline Apgar 1 & $7,6 \pm 1,9$ & $7,7 \pm 1,5$ & $>0,05$ \\
\hline Apgar 5 & $9,3 \pm 1,1$ & $9,3 \pm 0,7$ & $>0,05$ \\
\hline BMI & $27,1 \pm 2,5$ & $25,0 \pm 2,7$ & $<0,05$ \\
\hline $25(\mathrm{OH}) \mathrm{D}$ vit $(\mathrm{ng} / \mathrm{ml})$ & $11,8 \pm 8,0$ & $7,7 \pm 6,1$ & $<0,001$ \\
\hline$>30 \mathrm{ng} / \mathrm{ml}(\mathrm{N})$ & $4(\% 4)$ & $1(1 \%)$ & \\
\hline $20-30 \mathrm{ng} / \mathrm{ml}$ (insuff.) & $14(\% 13)$ & $5(5 \%)$ & \\
\hline $10-20 \mathrm{ng} / \mathrm{ml}$ (deficient) & $37(34 \%)$ & $18(18 \%)$ & \\
\hline$<10 \mathrm{ng} / \mathrm{ml}$ (severe def.) & $53(49 \%)$ & $78(77 \%)$ & \\
\hline
\end{tabular}

Mean age and BMI's were significantly higher in GDM group compared to control $(p<0,01)$. Gravidity, parity, birth week at labour, mean 1st and 5th minute Apgar scores were similar between GDM and control groups. Delivery modes were also similar between two groups. Mean 25(OH)D level was significantly higher $(11.8 \pm 8.0 \mathrm{ng} /$ $\mathrm{ml})$ in the study group compared to $(7.7 \pm 6.1 \mathrm{ng} / \mathrm{ml})$ control group $(\mathrm{p}<0,01)$ (Table 1).

Mean 25(OH)D level of all the cases was $9.81 \mathrm{ng} / \mathrm{ml}$ (SEM:0.51, SD: 7.42), upper bound and lower bounds were 10.85 and $8.84 \mathrm{ng} /$ $\mathrm{ml}$ respectively (at 95\% CI ). Minimum value was 3.0 and maximum was $49.0 \mathrm{ng} / \mathrm{ml}$. In distribution analysis of our cases, skewness was 1.82(SEM: 0.16) and kurtosis was 1.74 (SEM: 0.33) and 25(OH) D levels of the group participants were found to be normally distributed.

There were not any correlation of vitamin D levels with; maternal age, birth week, birth weight, first and fifth minute Apgar levels. There were either no correlation regarding 25(OH)D levels with mode of delivery $(p=0,93)$ and intensive care need of newborn $(p=0.36)$ and presence of macrosomia $(p=0.49)$.

New-born intensive care need and macrosomia rate were significantly higher in GDM group as expected, and no difference was found regarding the delivery modes between the groups.

\section{Discussion}

A number of studies examined associations between vitamin D status and GDM. Results from these studies ranged from negative to none or positive associations between vitamin D status and risk of GDM [1,6-8]. The meta-analysis of 20 studies showed vitamin D deficiency is associated with significantly increased risk for GDM [7]. On the other hand, some researchers did not observe associations of vitamin D deficiency with risk of GDM in studies conducted in Korea, North England [6,8]. Nicolaides group showed that first-trimester maternal 25(OH)D is not altered in GDM [8]. 
Based on Endocrine Society Guidelines, definitions of vitamin D status, 25(OH)D $\geq 30 \mathrm{ng} / \mathrm{mL}$ regarded as sufficiency and 25(OH)D $20-29.9 \mathrm{ng} / \mathrm{mL}$ as insufficiency, deficiency was defined as $25(\mathrm{OH})$ $\mathrm{D}<20 \mathrm{ng} / \mathrm{mL}$ and severe deficiency as $25(\mathrm{OH}) \mathrm{D}<10 \mathrm{ng} / \mathrm{mL}$ [3] .In this study, both group of patients had severe deficiency of 25(OH)D . $49 \%$ of the GDM group and $77 \%$ of the control group had severe deficiency.

Zhou, et al. study [10] in Chinese women, reported that prevalence of GDM was higher among women with higher 25(OH)D ( $\geq 30 \mathrm{ng} / \mathrm{ml}$ ) compared with women in the lower group. Our results are similar with Zhou's. They related higher prevalence of GDM in women with higher level of vitamin D, possibly to the older age and higher BMI of this group. Among numerous studies, only our study and Zhou's study are in concordance. Differences in results may be due to differences in diets or genetics. GDM group may be nourished better. Vitamin D induces insulin receptor expression through Vitamin D receptor, enhancing insulin-dependent glucose transport. Common genetic polymorphisms was found to be associated with 25(OH)D concentration [3]. Results may imply there may be difference in mechanisms of 25(OH)D pathway .

There is high prevalence of hypovitaminosis D among pregnant women in the Mediterranean regions (50-65\%) [9]. Reasons for this may rely on maternal darker skin pigmentation, poor dietary vitamin D intake, veiled clothing, reduced sunshine exposure, and increased prevalence of obesity. Our study group included such an undernourished, low income population. Although the climate is sunny, exposure to sunlight is limited, covered dressing is common. Some reports show that Mediterranean diets are associated with decreased risk of GDM [10]. Although our region is near Mediterranean, diet habits are

heterogeneous. So results are not related to Mediterranean diets or any specific habits. When we identified GDM patients in second trimester we studied their 25(OH)D vit levels. When we compared their levels with GDM negative patients', we found the levels of GDM group significantly higher. Although the levels of both groups were both under $20 \mathrm{ng} / \mathrm{ml}(11,8 \pm 8,0 \mathrm{ng} / \mathrm{ml}$ versus $7,7 \pm 6,1 \mathrm{ng} / \mathrm{ml}) \mathrm{p}<$ 0,001 ) , GDM group had significantly higher levels.

Obesity is considered a risk factor for GDM. Xu C, et al. [5] reported that combined vitamin D deficiency and obesity had OR of 4.66 for GDM. BMI of the GDM group was significantly higher as expected. It is well known that circulating 25(OH)D concentrations vary substantially over the year due to UVB; highest at the end of summer lowest at the end of winter, most studies report that $25(\mathrm{OH}) \mathrm{D}$ concentration is relatively constant, at least during the first two trimesters so we planned the study in second trimester of pregnancies in spring [5-8].

With the results of this study, we observed that Vitamin D deficiency is not associated with GDM in severely depleted population but the association might differ based on genetic or metabolic polymorphisms. Further studies are needed to clarify this.

\section{Acknowledgement}

None.

\section{Conflict of Interest}

Authors declare no conflict of interest.

\section{References}

1. Rodriguez A, García-Esteban R, Basterretxea M Lertxundi $A$, Rodríguez-Bernal C, et al. (2015) Associations of maternal circulating 25-hydroxyvitamin D3 concentration with pregnancy and birth outcomes. BJOG 122(12): 1695-1704.

2. Lacroix M, Battista MC, Doyon M, Houde G, Ménard J, et al. (2014) Lower vitamin D levels at first trimester are associated with higher risk of developing gestational diabetes mellitus. Acta Diabetol 51(4): 609-616.

3. Holick MF, Binkley NC, Bischoff-Ferrari HA, Gordon CM, Hanley DA, et al. (2011) Evaluation, treatment, and prevention of vitamin D deficiency: An endocrine society clinical practice guideline. J Clin Endocrinol \& Metab 96(7): 1911-1930.

4. Hartling L, Dryden DM, Guthrie A, Muise M, Vandermeer B, et al. (2012) Screening and diagnosing gestational diabetes mellitus. Evid Rep Technol Assess (Full Rep) 210: 1-327.

5. Xu C, Ma HH, Wang Y (2018) Maternal Early Pregnancy Plasma Concentration of 25-Hydroxyvitamin D and Risk of Gestational Diabetes Mellitus. Calcif Tissue Int 102(3): 280-286.

6. Park S, Yoon HK, Ryu HM, Han YJ, Lee SW, et al. (2014) Maternal vitamin D deficiency in early pregnancy is not associated with gestational diabetes mellitus development or pregnancy outcomes in Korean pregnant women in a prospective study. J Nutr Sci Vitaminol (Tokyo) 60(4): 269-275.

7. Zhang MX, Pan GT, Guo JF, Li BY, Qin LQ, et al. (2015) Vitamin D Deficiency Increases the Risk of Gestational Diabetes Mellitus: A Meta-Analysis of Observational Studies. Nutrients 7(10): 8366-8375.

8. Savvidou MD, Akolekar R, Samaha RB, Masconi AP, Nicolaides KH (2011) Maternal serum 25-hydroxyvitamin D levels at 11(+0) -13(+6) weeks in pregnant women with diabetes mellitus and in those with macrosomic neonates. BJOG 118: 951-955.

9. Zhou J, Su L, Liu M, Liu Y, Cao X, et al. (2014) Associations between 25-hydroxyvitamin D levels and pregnancy outcomes: a prospective observational study in southern China. Eur J Clin Nutr 68(8): 925-930.

10. Izadi V, Tehrani H, Haghighatdoost F, Dehghan A, Surkan PJ, et al. (2016) Adherence to the DASH and Mediterranean diets is associated with decreased risk for gestational diabetes mellitus. Nutrition 32(10): 10921096. 